\title{
Ecocentrism in Practice:
}

\section{A Search for Nodes on Humanity's Immune System}

\section{David Anthony Pittaway}

\section{Abstract}

In this paper, the ecological crisis and the physical anthropogenic causes of it are taken as axiomatic. With this crisis and its physical causes as backdrops, the issue of attitudinal causes of the crisis will preliminarily be focused on. Lyn White Juniour's take on the issue will be considered briefly, as will Pierre Hadot's descriptions of the Promethean and Orphic attitudes. The central question of this paper will then be asked: what do ecocentric attitudes entail? A broad literature review is offered in order to illustrate aspects of eligible attitudinal components: older cultures; the unnamed movement traced by Hawken in Blessed Unrest; the Occupy Movement, Eisenstein's model of a sacred economy, and some aspects of Deep Ecology. These examples of ecologically sensitive, ecocentric attitudes can be looked at as points on humanity's immune system, a system that may become increasingly important as the systems historically dominating humanity buckle under the pressure of ailing ecosystems and economies.

Keywords: dominion-imperative, interconnection, cooperation, natural principles, Joel Kovel, capitalism, resources, inherent value, instrumental value

\section{Introduction}

Humanity is confronted by an unprecedented ecological situation. Whether one regards the situation as a crisis or a problem is a semantic issue. The facts have been made clear by numerous reputable sources: various ecological indicators 
depict a rapid decline in the health of global ecology. Earth's life-support systems have been destabilised and jeopardised, with human activity and industry propelling the decline. Literature and data about the decline and the anthropogenic causes of it are widely available, with good examples being the World Wildlife Foundation's 2016 Living Planet Report, Diamond's 2005 Collapse, Kovel's 2006 Enemy of Nature, and a seemingly endless array of articles such as Baronsky et al.'s 2012 'Approaching a State Shift in Earth's Biosphere'. I have explored the ecologically devastating consequences of numerous largescale human industries elsewhere (Pittaway 2017) and do not wish to engage further with what has for a considerable length of time been acknowledged to be their deleterious ecological consequences. What I do wish to focus on here, for the sake of laying part of the conceptual foundation of this paper, is White's comment (1967:1205), 'What people do about their ecology depends on what they think about themselves in relation to the things around them'.

In his paper, 'The Historical Roots of Our Ecological Crisis', which was published in the Journal Nature in 1967, White identified Christianity, technology and science as being instrumental shapers of discourse, propelling attitudes that in turn give impetus to large-scale ecologically problematic activities. The dominion-imperative is common to Christianity, reductionist science and exclusively pragmatic-utilitarian technology. White never mentioned capitalism in his essay, but it surely must be added to the list considering its pernicious grow-or-die drive that is a demonstrable disaster for ecology (Kovel 2006). This focus on attitudes that underlie ecologically consequential action is important, because it more extensively enables one to understand cause-and-effect relations at work in the context of the ecological crisis than does the common focus on purely physical causes. It is a relatively straightforward task to identify several large-scale human industries as the primary causes of the ecological crisis, but, taking White's analysis into consideration, those industries have been created by human beings with attitudes, ideologies, beliefs, and assumptions about their place in nature which direct their actions and which in turn impact on ecology. Pierre Hadot (2008:91-98) summarises the kinds of attitudes that motivate ecologically destructive actions as 'Promethean'. He says that the Promethean is 'inspired by audacity, boundless curiosity, the will to power, and the search for utility' and it 'penetrates the secrets of nature ... through violence', pointing out that this attitude has 'engendered our modern civilization and the worldwide expansion of science and industry'. 
Much has been written in the academic world about the problems of the Promethean, though the term Promethean is not directly employed. On the other hand, there is a scarcity of writing about attitudes that are not hostile to nature, ecocentric attitudes that may motivate action towards ecologically sensitive ends. Hadot (2008:91-98) refers to these kinds of attitudes towards nature as Orphic attitudes. An Orphic attitude 'penetrates the secrets of nature not through violence but through melody, rhythm, and harmony', and he points out that it 'is inspired by respect in the face of mystery and disinterestedness'. In this paper I aim to provide, in part, an answer to the question, what do ecologically sensitive, Orphic features and characteristics look like? This is a crucial question to ask, because human beings have, at an increasing speed, devoured the natural systems on which human and non-human life depend for survival. The ecological crisis is a reminder that the Promethean experiment has a shelf-life, and it is foolish to believe that from within the realms of the dominant Promethean paradigm solutions to the ecological crisis will be found - the acceleration of rates of ecological destruction is proof of this. As White suggests (1967:1204), until we 'think about fundamentals,' 'clarify our thinking,' and 'rethink our axioms', the ecological crisis will not adequately be addressed. This paper participates in this process.

Until we engage with the process mentioned by White - thinking about fundamentals, clarifying our thinking, rethinking our axioms - and act upon the outcomes in a response to ecological problems, humanity's collective immune system may be left lacking. Paul Hawken, talking about a broader role played by the 'unnamed movement' he identifies in Blessed Unrest (2007:141142), suggests something that is relevant in light of the Orphic offerings that feature in this paper: the 'capacity to respond', says Hawken, 'would function like an immune system, which operates independently of an individual person's intent. Specifically, the shared activity... can be seen as humanity's immune response to toxins like political corruption, economic disease, and ecological degradation'. This paper comprises a literature review of some nodes on this important immune system.

\section{Older Cultures}

Hartmann (1998:154) lists the Kogi, the Ik of Uganda, the Najavo, the Hopi, the Cree, Ojibwa and the San as examples of older cultures, though this list is by no means exhaustive. He identifies the following as important characteris- 
tics of older cultures, characteristic that stand out as ecocentric and Orphic in nature. The first is the view, commonly associated with older cultures, that human beings 'are part of the world'. The second is the view that it 'is our destiny to cooperate with the rest of creation'. These are very simple ideas, but together they stand in strong opposition to the modus operandi of Promethean businessas-usual. McDonough and Braungart offer the resonating sentiments of a member of an older culture, Oren Lyons, 'faith keeper of the Onondaga' (2002:i), as one of three opening quotes to their important book Cradle to Cradle: 'What you people call your natural resources our people call our relatives'. This corresponds to Hartmann's findings (1998:154): older cultures 'are most often cooperators, not dominators' and 'the anthropological record shows that not one culture believed itself to be separate from and superior to nature'.

Vetlesen (2012:38) confirms the general picture of older cultures painted above by Hartmann, and offers an extract of research on the Cree (a North American aboriginal group) conducted by Berkes wherein it is pointed out that for this older culture 'there is no waste'. This is an important feature of older cultures. The principle of not wasting is central to McDonough and Braungart's work (2002:92), and they devote a full chapter to the principle: 'Nature operates according to a system of nutrients and metabolisms in which there is no such thing as waste'. They argue at various stages in their book that human beings must create systems that replicate nature's system if a truly sustainable human dispensation is to be achieved. Considering what has been glimpsed about older cultures (and what will still be glimpsed), it is perhaps the case that concerted efforts to elevate remaining members of older cultures in contemporary culture is a step in the direction of re-opening Orphic channels via the remembrance and acceptance of older ways of thinking and living. These ways of thinking and living have clear implications for ecology. As Vetlesen points out (2012:37):

Studies of indigenous cosmologies demonstrate how ... [e]verything in the environment is considered to have life and spirit. A traditional conservation ethic can thus be defined as 'the awareness of one's ability to damage natural resources, coupled with a commitment to reduce or eliminate the problem.

J. Callicott (quoted by Vetlesen 2012:38) provides information pertaining specifically to American Indian culture that further describes the 


\section{David Anthony Pittaway}

ecocentric and Orphic attitudes and ways of older cultures, and he also spells out further implications for what the attitude means for ecology:

The implicit overall metaphysic of American Indian culture locates human beings in larger social, as well as physical, environment. Existence in this larger society places people in an environment in which reciprocal responsibilities and mutual obligations are taken for granted without question or reflection. All creatures, be they elemental, green, finned, winged, or legged, are children of one father and one mother. One blood flows through all; one spirit has divided itself and enlivened all things with a consciousness that is essentially the same. The world around, though immense and overwhelmingly diversified and complex, is bound together through bounds of kinship, mutuality, and reciprocity.

In keeping with this ecocentric ethic, a Native American chief of the Wanapum tribe speaks words that powerfully reinforce the point that older cultures share a deep kinship with the earth that fosters ecological equanimity. Here the chief is explaining 'why he refused to till the ground' (quoted in Sheldrake 1994:13):

Shall I take a knife and tear my mother's bosom? Then when I die she will not take me to her bosom to rest. You ask me to dig for stone! Shall I dig under her skin for her bones? Then when I die I cannot enter her body to be born again. You ask me to cut grass and make hay and sell it. And be rich like the white men! But how dare I cut off my mother's hair?

Setreng (2012:105) provides an example of how older cultures' worldviews further translate into physical action with the natural environment. He asks one to consider 'A Sherpa house in Nepalese Himalaya'. It,

always appears 'unfinished', a creation that never reached its 'destined geometrical perfection'. But, from the traditional Sherpa point of view, the beauty and, intimately connected with that, the utility of the house may only be discovered if you settle down for a couple of generations, build such a house yourself, take responsibility for its daily care, live with the house instead of being its architect, repair it when (the frequent) need arises, add to it or subtract from it ... 
Record a hundred years of the development of the house at a frame a day and play it back at 'normal cinematic speed':

What will be revealed to you, is not a house in the Western sense, but an organic structure, its wall stones and roof materials will be moving about and changing, ... the animal and human life around it will expand and contract, speed up and slow down, shift in kind and variety... This is a house that is decaying every day, a fact which is accepted by the people that are part of this 'house-hold'.

The juxtaposition to the building characteristics of so-called advanced industrial civilisation is clearly enormous considering that its industry is epitomised by the production and application of cement, a substance that requires massive amounts of energy to produce and transport and hence has considerable negative environmental impact. Once cement has been used, it is bound to remain in its specific shape and form for many decades as something that is supposed to be impervious to nature's cycles. If a person were to do something similar - record a hundred years of the development of the house at a frame a day and play it back at 'normal cinematic speed' - the building will not change much (despite the huge quantities of energy typically used in buildings to heat and cool them), but instead it stands out as separate to the natural cycles that surround it. Setereng's example of a Sherpa house provides a glimpse of how the worldviews and attitudes of members of older cultures give impetus to act in ecocentric ways - in this instance, to build more organically. The kinds of cement-based buildings lionised in advanced industrial society, and the formidable bureaucracies that exist to enforce building regulations, perhaps reveal something of its underlying ecocidal worldviews and attitudes.

By way of summary the words of Vaclav Havel (1994:2) may be added to the preceding discussion, especially the point about 'our ancestors', which is to say members of older cultures:

Classical modern science described only the surface of things, a single dimension of reality. And the more dogmatically science treated it as the only dimension, as the very essence of reality, the more misleading it became. We may know immeasurably more about the universe than our ancestors did, and yet it increasingly seems that they knew something more essential about it than we do, something that escapes us (e.a.). 


\section{David Anthony Pittaway}

What comes across is the notion that respect for nature is respect for oneself. As David Abram (1996:ix) states in his Spell of the Sensuous: We 'are human only in contact, and conviviality, with what is not human' - the members of older cultures clearly lived according to this ecologically sensitive ethic. This seems to have been forgotten in a world dominated by Promethean attitudes and assumptions, perhaps explaining in part why the ecological crisis arose in the first place. It may be in the remembrance of the human connection with nature that ecologically sensitive ways of living can be reconstructed, and members of older cultures may be able to enlighten Promethean 'man' in this regard if they are given more chance to do so.

\section{Hawken's Blessed Unrest}

'Hardt and Negri, quoted by Baer (2012:303), state that 'only movements from below' possess the 'capacity to construct a consciousness of renewal and transformation', and Paul Hawken's Blessed Unrest is a book about such movements: 'coherent, organic, self-organised congregations involving tens of millions of people dedicated to change' (Hawken 2007:4). At the time of the book's publication, the movement was constituted by between one and two million organisations 'working towards ecological sustainability and social justice' (2007:2). Hawken (2007:3) is quick to point out that by conventional standards, the movement is unusual in that it has no leaders or ideologies:

This movement... doesn't fit the standard model. It is dispersed, inchoate, and fiercely independent. It has no manifesto or doctrine, no overriding authority to check with. It is taking shape in schoolrooms, farms, jungles, villages, companies, deserts, fisheries, slums - and yes, even fancy New York hotels. One of its distinctive features is that it is tentatively emerging as a global humanitarian movement arising from the bottom up. Historically social movements have arisen primarily in response to injustice, inequalities, and corruption. Those woes still remain legion, joined by a new condition that has no precedent: the planet has a life-threatening disease, marked by massive ecological degradation and rapid climate change[;] ... perhaps [this is] the growth of something organic, if not biologic. Rather than a movement in the conventional sense, could it be an instinctive, collective response to threat? 
Already stated above is the rough figure of one to two million organisations worldwide. Clearly apparent is the range of organisation types that constitutes it - a notably heterogeneous mix. Hawken used the website called Wiserearth.org at the time of writing his book to ascertain the size of the unnamed movement. Having closed its database in 2014, it is not possible to see the change in numbers of organisations that currently participate in the unnamed movement. However, Hawken included the database category summaries and sizes in his book as an appendix - an appendix 107 pages long (2007:195-302). An example sub-section is called 'Greening of Industry' (2007:248), in which it is recorded that in 2007 there were 4346 listed organisations focused on Recycling and Reuse, 178 on Sustainable Materials, and 258 on Sustainable Production. A continued perusal of the appendix reveals a vast range of sub-sections - energy, fisheries, health, sustainable cities and design, media, work, etc. - all of which have numerous listed areas of focus where the number of associated organisations are tallied; and the numbers are considerable in size.

Hawken provides very clear examples of alternative living practices that are associated with the movement (2007:175):

[T] he way to change the world is to change one's own practices, including one's home, source of energy, method of agriculture, diet, transport patterns, and communities. ... [Y]ou can't get there from here by any mechanism that depends on support from institutions that benefit from the status quo. ... [P] eople [must] re-examine how they behave and consume in their own lives. The movement can be seen as weak when measured against large institutions, but its goals are more important. The goal is to create a more resilient social and economic understory in what is basically an oligarchic world, a powerful act that restores a measure of autonomy and power to citizens.

Individual action is clearly emphasised as being of the utmost importance in responding to the ecological crisis (as well as to a variety of issues), while large-scale institutionalised processes are cast into doubt in this regard. Much more than mere voting is needed as a response from members of the public as their social and political participation, and the organisations constituting the unnamed movement all offer parts of what Hawken calls a resilient understory for people to tap into and thereby gain orientation regarding how to take prac- 


\title{
David Anthony Pittaway
}

tical steps towards sustainability. Accordingly, Hawken employs a biological or organic metaphor for the movement, and he raises the important notion of humanity's immune system, which was referred to as part of the general role of the Orphic in the introduction to this paper. He writes (2007:141-142),

\begin{abstract}
The movement is that part of humanity which has assumed the task of protecting and saving itself. If we accept that the metaphor of an organism can be applied to humankind, we can imagine a collective movement that would protect, repair and restore the organism's capacity to endure when threatened. If so, that capacity to respond would function like an immune system, which operates independently of an individual person's intent. Specifically, the shared activity of hundreds of thousands of nonprofit organizations can be seen as humanity's immune response to toxins like political corruption, economic disease, and ecological degradation.
\end{abstract}

Here is a powerful resonance with a more organic view of life on the planet, one where human beings are seen as part of nature, and accordingly it resonates with the ecocentric, Orphic attitude shared by members of various older cultures. The unnamed movement is spread across the globe, which is reason for optimism in the face of the pessimistic ecological situation faced by humankind - there is something of a network that constitutes an immune system against the dominance of Promethean systems, a network that a person or a group of people can tap into if they wish to participate in a process towards the ecological justice necessary for all life to co-exist on the planet.

\section{The Occupy Movement}

Numerous aspects of the Occupy Movement of 2011 and 2012 point towards resonance with the ecocentric, Orphic attitude, and towards direct resistance to aspects of purely Promethean paradigms. The tents and camps that were explicit symbols of the Movement when it was manifesting in places like Wall Street in the USA and around St Paul's Cathedral in front of the London Stock Exchange may no longer be erected, but as will be seen in this sub-section, the spirit of the phenomenon lives on. One of the main catch-phrases of the Movement is 'We are the 99\%', words that signify an awareness of the significantly uneven distribution of wealth that reputable critics like Piketty 
(2014) argue is created and perpetuated by capitalism. In an Oxfam report by Deborah Hardoon called 'An economy of the 99\%', attention is drawn to the following disproportion in wealth (2017:1): just 'eight men own the same wealth as the poorest half of the world'. It tends to be the case that such statistics vary somewhat according to source, which is expectable considering the various different indices that can be taken into account when working out such a challenging statistic, but regardless of the differences between the various attempts to work out the exact statistics, the conclusion is unavoidable: the top $1 \%$ of the 'super-rich' and 'super-wealthy' people of the world own and control more wealth and assets than the vast majority of the world's population combined. The Occupy Movement was partly a response to such a skewed distribution of the world's wealth, but more importantly, the movement was responding to the ethically reprehensible consequences of various actions that have had global economic impacts that further benefit the $1 \%$ but deteriorate living conditions for the $99 \%$. These issues are evident in what one of the official 'Occupy' webpages (still online in 2018) summarises about the movement: 'Occupy' fights back,

against the corrosive power of major banks and multinational corporations over the democratic process, and the role of Wall Street in creating an economic collapse that has caused the greatest recession in generations. The movement is inspired by popular uprisings in Egypt and Tunisia, and aims to fight back against the richest $1 \%$ of people that are writing the rules of an unfair global economy that is foreclosing on our future.

An example of problematic actions perpetrated by what the Occupy Movement interchangeably called 'the 1\%', 'Wall Street', 'banksters' or 'Corporations', was the economic crisis that started in 2008. Members of the Occupy Movement frequently point out that the crisis was orchestrated by the banking sector, a sector in which highly instrumental players of 'the 1\%' reside. The economic crisis of 2008 is a complicated matter, but there are some very clear reasons for why it occurred, as summarised by Michele Fratianni and Francesco Marchionne (2009:1) in a paper called 'The Role of the Banks in the Subprime Financial Crisis':

[L]arge default rates on subprime mortgages cannot account for the 


\section{David Anthony Pittaway}

severity of the crisis. Rather, low-quality mortgages acted as an accelerant to the fire that spread through the entire financial system. The latter had become fragile as a result of several factors that are unique to this crisis: the transfer of assets from the balance sheets of banks to the markets, the creation of complex and opaque assets, the failure of ratings agencies to properly assess the risk of such assets, and the application of fair value accounting. To these novel factors, one must add the now standard failure of regulators and supervisors in spotting and correcting the emerging weaknesses.

The above provides support for what was explored in Inside Job, a 2010 documentary that traces the role of the banks in an economic crisis that affected economies worldwide. As stated by Phillip Inman and Patrick Kingsley in a Guardian.com review, Inside Job focuses on a 'villainous lineup that includes bankers, politicians (many of whom were previously bankers), regulators, the credit ratings agencies and academics'. The reviewers state that there 'are plenty of economists who believed the banks understood what they were doing and supported deregulation'. The details of these kinds of issues are beyond the scope of this article, but one thing is obvious: when the banking industry falters - and Inside Job shows that various authorities allowed the industry to falter - it is the general public that has to bail it out, as pointed out by Fratianni and Marchionne (2009): 'the crisis persists and governments continue to inject vast amounts of public funds into banks'. In light of the 2008 financial crisis, David Harvey, in his Enigma of Capital and the Crisis of Capitalism, traces the development of the process by which policy has been structured to give the banks a free ride, so to speak, one paid for with public funds. He clearly agrees (2010:10-11) that the behaviour of the banks is extremely problematic:

One of the basic pragmatic principles that emerged in the 1980s, for example, was that state power should protect financial institutions at all costs. ... Put crudely, the policy was: privatise profits and socialise risks; save the banks and put the screws on the people (in Mexico, for example, the standard of living of the population dropped by about a quarter in four years after the financial bail-out of 1982). The result was what was known as 'systemic moral hazard'. Banks behave badly because they do not have to be responsible for the negative consequences of high-risk behaviour. The... bank bail-out [of 2008] is 
this same old story, only bigger and this time centred in the United States.

This is all indicative of an economic system structured to favour the richest people in society. Members of the Occupy Movement rejected this kind of system that has via globalisation taken hold throughout the world, and Occupiers actively experimented with a direct participatory democracy, as pointed out by Ian Buchanan in 'September 17, 2011: Occupy without Counting' in Occupy: A People yet to Come, edited by Andrew Conio. Buchanan (2015:193) says that the Occupy Movement's,

production was an example of participatory democracy in action - the set of principles the occupiers wanted to live by was created and embraced by the occupiers themselves. All proposals required the support of at least $90 \%$ of the General Assembly in order to be ratified, which is far more onerous than parliamentary democracies anywhere else requires. And of course that was precisely the point: it demonstrated that democracy as we know it, that is, democracy as it is practiced in the United States and elsewhere is a pale shadow of 'true' democracy, which is open to all and premised on the notion that only near-consensus can be regarded as representative of the will of the people. As impractical as this model of democracy might be, its symbolic value should not be underestimated. It bespoke a powerful hunger for social justice, for a political and economic system that represents the needs of the many not the greed of the few that not even President Obama could fail to perceive.

Furthermore, members of the Occupy Movement share an acute awareness that endless growth is inherent in a capitalist debt-based monetary system and that the impact of such continued growth has deleterious consequences for the wellbeing of natural ecologies. The following from Russell McLendon (2011) reveals the views of a prominent academic, namely Bill McKibben, who took part in the Occupy movement:

'For too long, Wall Street has been occupying the offices of our government, and the cloakrooms of our legislatures', wrote Bill McKibben, co-founder of 350.org, in an email to supporters before 
the march. 'They've been a constant presence, rewarded not with pepper spray in the face but with yet more loopholes and tax breaks and subsidies and contracts. You could even say Wall Street's been occupying our atmosphere, since any attempt to do anything about climate change always run afoul of the biggest corporations on the planet. So it's a damned good thing the tables have turned'.

This comment by McKibben was made in 2011, during the height of the occupation of places like Wall Street and St Paul's Cathedral by members of the Occupy Movement. However, McKibben's final remark - that the tables have turned - did not refer to an immediate event, as the comment seems to suggest, because since then, as stated by Paul Mason in 2015,

in the absence of any alternative model, the conditions for another crisis are being assembled. ... The shadow banking system has been reassembled, and is now bigger than it was in 2008. New rules demanding banks hold more reserves have been watered down or delayed. Meanwhile, flushed with free money, the $1 \%$ has got richer.

The title of the article from which the above quote is taken is 'The End of Capitalism has Begun', a title that reveals a sentiment with which the members of the Occupy Movement in general certainly agreed. McKibben's remark about the tables turning, then, must be understood in the sense of the so-called end of capitalism being a process rather than being one exact event. In some ways, the Occupy Movement can be seen as the biggest and most influential global uprising in history, and the impact of the movement has been widespread. In an interview hosted by Jonathan Derbyshire (2014), David Harvey said the following about the extensive reach of 'the Movement':

I credit the Occupy movement with sparking that new conversation a conversation that highlights the wealth inequalities all over the world. ... It's interesting that everybody knows what you're talking about when you mention the 'one per cent'. The issue of the one per cent is now on the agenda and given depth by studies like that of Thomas Piketty, in his book Capital in the Twenty-First Century. Joseph Stiglitz has a book on inequality, too, and several other economists are talking about it. Even the IMF is now saying that there 
is a danger that follows when inequality reaches a certain level. Even Obama is saying it. But Obama wouldn't have said it if Occupy hadn't done so first.

Harvey does point out, however, that as far as actual policy goes - policy from the governmental sphere that has direct implications for what is permissible in terms of corporate action that furthers economic inequality, ecological degradation, etc. - little is being done. The Occupy Movement may not have had an impact when it comes to the major political changes that would help to diminish the pernicious effects of Promethean corporatism, but certainly the Movement can be credited with raising near-global awareness about the purely Promethean attitudes, phenomena, and mechanisms, and with furthering the search for ecocentric and Orphic alternatives.

I have just mentioned a search for Orphic alternatives, a search the Occupy Movement has assisted in, especially with regard to raising awareness about alternatives and the need to pursue them. In this light, two references need to be made. The first comes from the book already mentioned in this subsection, Occupy: A People yet to Come, edited by Andrew Conio. In the introduction to the book, Conio writes the following (2015:25), which elaborates appropriately on the notion of the Occupy Movement having sparked a new conversation (as mentioned by Harvey, above), a conversation that can equally be said to be necessary in the search for ecocentric attitudes and systems:

The Occupy movement ... created a new environment in which discussions that might once have seemed impertinent have been gaining a new traction. 'Occupy' is a synecdoche for belief in the revolutionary transformation of the capitalist system: a new heterogenic world of protest and activism that cannot be thought in terms of the state, liberal Democracy, parliamentary systems, or the hugely compromised nongovernmental organisation (NGO) sector. Nor can Occupy be conceived in terms of class war or vanguard politics. These conceptualisations do not articulate fully where power is held, nor from where revolution may issue. A philosophical vocabulary that would materially inhabit the conditions of our present global world order is needed because the different registers of ontology (the movements of the earth), the social (the people yet to come), epistemology (concept formation), and aesthetics are 
nevertheless activated on the one single plane that is at considerable remove from the conventional terms of state or royal politics as they are understood today.

The second reference is to something Manuel Castells says in response to a question asked to him in an interview led by Paul Mason in a BBC interview (2012). The interview is mainly about themes raised in the book Aftermath: The Cultures of the Economic Crisis, edited by Manuel Castells, J. Caraca and G. Cardoso. This is Castells' response to a question by Mason about how big this cultural change is, a change that Occupiers were trying to participate in:

It is fundamental because it triggers a crisis of trust in the two big powers of our world: the political system and the financial system. People don't trust where they put their money and they don't trust those who they delegate in terms of their vote. All the statistics are there. It's a dramatic crisis of trust and if there is no trust, there is no society.

To state the obvious, there is also no society if the ecological platform on which society depends for survival is destabilised to such an extent that social systems eventually crumble, a destabilisation that the political system and the economic system do nothing to improve when they actively promote the Promethean attitudes (such as addiction to endless growth) that motivate actions that undermine ecological stability. The Occupy Movement, in participating in the kinds of novel processes referred to by Conio, acted in part to actualise alternative attitudes, ways of thinking, and ways of being-together that have potentially ecocentric outcomes.

\section{Eisenstein's Sacred Economics}

Charles Eisensteins' Sacred Economics: Money, Gift and Society in the Age of Transition (2011) embodies the perspective of a writer who has thoroughly adopted an Orphic paradigm, a perspective with important implications for what an alternative economy would look like. The importance of envisioning an alternative economy is explained by Baer (2012:203 - 204):

While the powers that be around the world are seeking to address cli- 
mate change within the parameters of global capitalism, as Simms ... observes, 'global warming probably means the death of capitalism as the dominant organising framework for the global economy.' Thus, it is imperative to think outside the box and construct an alternative to global capitalism as the ultimate climate mitigation strategy, even though it will not be achieved any time soon, if indeed ever.

Eisenstein's thinking is clearly 'outside the box', and his use of the word 'sacred' in the book's title is an immediate hint that he advocates an economy unlike anything familiar in the capitalist world. There is nothing sacred about global capitalism's debt-based and growth-based economy, as evidenced by its ubiquitous negative ecological impacts. Eisenstein states early on in the text that the purpose of the book is 'to make money and human economy as sacred as everything else in the universe' (2011:5). This clearly implies that Eisenstein views the universe and its content as 'sacred', something that is completely incompatible with the materialist, reductionist, and consumer-capitalist characteristics, where all that exists is seen by human beings as resources (Heidegger 1977). His opposition to these exclusively Promethean characteristics can be seen in the following quote, as well as what he means by the word 'sacred', and further what kind of economic system he raises issue with. He writes (2011:9) that 'the sacred' is,

the gateway to the underlying unity of all things, [and] it is equally a gateway to the uniqueness and specialness of each thing. A sacred object is one of a kind; it carries a unique essence that cannot be reduced to a set of generic qualities. That is why reductionist science seems to rob the world of its sacredness, since everything becomes one or another combination of a handful of generic building blocks. This conception mirrors our economic system, itself consisting mainly of standardized, generic commodities, job descriptions, processes, data, inputs and outputs, and - most generic of all - money, the ultimate abstraction.

The analysis conducted in Sacred Economics leads to several intriguing approaches that are useful for what can loosely be called the furthering of the ecologically respectful Orphic agenda. Eisenstein summarises several of these approaches in Chapter 17 of Sacred Economics (2011:228 - 237): 
1) Negative-interest currency;

2) elimination of economic rents, and compensation for depletion of the commons;

3) internalisation of social and environmental costs;

4) economic and monetary localisation;

5) the social dividend;

6) economic degrowth; and

7) gift-culture and $\mathrm{P} 2 \mathrm{P}$ economics

He points out (2011:237) that 'all of the seven elements I have described are tightly synergistic. Indeed, none can stand on its own'. Nevertheless, only the notion of internalising costs will be considered here as an example of a sacred economy's ecocentric character. The internalisation of costs is the opposite of the dominant Promethean approach whereby costs are externalised. Externalised costs are ones 'that someone else pays' (2011:195):

For example, one reason vegetables from California's Central Valley are cheaper to buy in Pennsylvania than local produce is that they don't reflect their full cost. Since producers are not liable to pay the current and future costs of aquifer depletion, pesticide poisoning, soil salinization, and other effects of their farming methods, these costs do not contribute to the price of a head of lettuce. Moreover, the cost of trucking produce across the continent is also highly subsidized. The price of a tank of fuel doesn't include the cost of the pollution it generates, nor the cost of the wars fought to secure it, nor the cost of oil spills. Transport costs don't reflect the construction and maintenance of highways. If all these costs were embodied in a head of lettuce, California lettuce would be prohibitively expensive in Pennsylvania. We would buy only very special things from faraway places.

This illustration refers to numerous ecological issues resulting from large-scale Promethean industries - water issues, soil issues, pesticide poisoning, pollution, and ever-expanding transport systems. Eisenstein is making the direct link between an economic approach, namely capitalism's externalisation of costs, and these kinds of ecological issues. The Orphic character of internalising costs stands out in the following from Eisenstein: the 'internalization of 
all costs is simply the economic embodiment of that principle of interbeingness: 'As I do unto others, so I do unto myself'" (2011:126). Kovel (2007:16) places this idea of interbeing into a broader context: 'It is the essential nature of ecosystems for each to be bounded and internally related, on the one hand, and connected to all other ecosystems, on the other. Thus nature, which we read at this end, may be defined as the integral of all ecosystems'. The internalisation of costs is one characteristic of a sacred economy - a sacred economy 'is an extension of the ecology and obeys all of its rules, among them the law of return' (2011:124). Eisenstein describes the law of return as follows:

In an ecology, no species creates waste that other species cannot use - hence the maxim, 'Waste is food.' No other species creates growing amounts of substances that are toxic to the rest of life, such as dioxin, $\mathrm{PCBs}$, and radioactive waste. Our linear/exponential growth economy manifestly violates nature's law of return, the cycling of resources.

In Cradle to Cradle, McDonough and Braungart make exactly the same point. A chapter in the book (2002:92-117) is called 'Waste equals food'. In the example above of the Californian lettuce in Pennsylvania, application of the internalisation of costs principle would quite simply mean that one would eat local organic lettuce rather than the one trucked in from afar. In the debt-based money system, this may mean initially paying more for the local organic lettuce. However, Eisenstein states in Sacred Economics that the debt-based Promethean monetary system is reaching its end: 'Today, it seems, we are reaching the limits of growth, and therefore the end of humanity's childhood' (2011:68), and ' $[\mathrm{w}]$ hat we see with alarm as an exponential growth curve is actually part of a phase transition curve' (2011:175). Accordingly, he offers numerous alternative means of economic interaction. These alternatives cannot be explored here, but the following from Eisenstein (2011:132 - 133) will be offered in order to convey the Orphic character of his approach. Here he is describing the notion of a commons-backed currency:

Once we have decided how much of each commons should be made available for use, we can issue money 'backed' by it. For example, we might decide that the atmosphere can sustain total sulfur dioxide emissions of two million tons a year. We can then use the emissions 
rights as a currency backing. The same goes for the rest of the commons. The result would be a long list comprising all the elements of the commons we agree to use for economic purposes. Conceptually, it might look something like this: Our money derives its value from the right to harvest 300,000 tons of cod from the Newfoundland cod fishery, the right to draw 30 million gallons of water monthly from the Ogallala Aquifer, the right to emit 10 billion tons of $\mathrm{CO} 2$, the right to pump 2 billion barrels of oil from the ground, the use of the Xmicrohertz band of the electromagnetic spectrum ....

The above extract is an illustration of a commons-backed currency at work, and is notably unlike purely quantitative debt-based currency familiar in Promethean worldviews where nature is reduced to a 'standing reserve' of resources (Heidegger 1977: 4,19-20). A commons-backed currency is determined not by the value of resource extraction, but rather by prioritizing the quantitative and qualitative well-being of nature as something with which human beings commune. The latter worldview holds that nature offers gifts to human beings, gifts that human beings can accept only with a strong sense of humility and responsibility. It is a worldview shared by various ecocentric ancestors of humankind. It is also one that will have to be adopted at large by human beings again if ecological stability is to be taken as a serious goal.

\section{Deep Ecology}

An appropriate starting point for this sub-section is the distinction drawn by Arne Naess (2008:99-100) between the shallow and deep ecological movements. Shallow ecology, Naess observes, has 'started to have an impact on the government level. Environmental organisations are listened to, and their advice has occasionally been used in practice. But future generations of nonhumans seem to be valued publicly only for the sake of future humans'. Naess is clearly describing an instrumentalist approach to valuing nature, and a strong anthropocentric focus is evident. Naess then contrasts shallow ecology to deep ecology in a manner where an ecocentric commitment is immediately clear. He mentions (2008:100) the goal of 'the protection of the planet and its richness and diversity of life for its own sake' (Naess' emphasis) - valuing nature 'for its own sake' is simply another way of describing the valuing of nature for its inherent value, which is a key attitudinal component of 
ecocentrism. Naess states further (2008:102) that the 'all-around maturity of humans facilitates acts of identification with every kind of living being', which resonates with the attitudes espoused by various older cultures.

Naess (2008:111) summarises the eight defining points of the deep ecology perspective as follows; it is instantly clear that these eight points are explicitly ecocentric and Orphic in character:

1) The flourishing of human and nonhuman life on earth has inherent value. The value of nonhuman life-forms is independent of the usefulness of the nonhuman world for human purposes.

2) Richness and diversity of life-forms are also values in themselves and contribute to the flourishing of human and nonhuman life on earth.

3) Humans have no right to reduce this richness and diversity except to satisfy vital needs.

4) The flourishing of human life and cultures is compatible with a substantial decrease of the human population. The flourishing of nonhuman life requires such a decrease.

5) Present human interference with the nonhuman world is excessive, and the situation is rapidly worsening.

6) In view of the foregoing points, policies must be changed. The changes in policies affect basic economic, technological, and ideological structures. The resulting state of affairs will be deeply different from the present and make possible a more joyful experience of the connectedness of all things.

7) The ideological change is mainly that of appreciating life quality (dwelling in situations of inherent value) rather than adhering to an increasingly higher standard of living. There will be a profound awareness of the difference between big and great.

8) Those who subscribe to the foregoing points will have an obligation directly or indirectly to participate in the attempt to implement the necessary changes.

In deep ecology, all life has inherent value. Naess (2008:112) qualifies what is meant by 'life': the 'term life is used here in a comprehensive, nontechnical way to refer also to what biologists classify as nonliving: rivers (watersheds), landscapes, cultures, ecosystems, the living earth'. It is not possible in the deep ecology movement to view 'life' in its broader sense as a 'standing reserve' of 


\section{David Anthony Pittaway}

resources (Heidegger 1977: 4,19-20), nor for a human being to consider himor herself to have dominion over the rest of the living and non-living world. Considering that Promethean 'man' has historically considered himself to have dominion over the rest of the living and non-living world, and in light of the value attributed to life in its broader sense in deep ecology, it is unsurprising that Hoyer (2012:57) says of Naess that he 'considers deep ecology to be a movement encouraging people to thoroughly question the fundamental presumptions underlying the dominant economic approach of Western society in terms of value priorities, philosophy and religion'. Accordingly, the richness and diversity of life forms is prioritised as intrinsically/inherently valuable.

Finally in this sub-section, I will list the 25 lifestyle trends within the deep ecology movement identified by Naess (2008:140-141). These points elaborate on what living according to a deep ecology ethos entails, and add further details that clearly depict an ecocentric, Orphic lifestyle:

1) Use simple means; avoid unnecessary, complicated instruments and other sorts of means.

2) Choose activities most directly serving values in themselves and having intrinsic value. Avoid activities that are merely auxiliary, have no intrinsic value, or are many states away from fundamental goals.

3) Practice anticonsumerism. This negative attitude follows from trends 1 and 2.

4) Try to maintain and increase the sensitivity and appreciation of goods in sufficient supply for all to enjoy.

5) Eliminate or lessen neophilia - the love of what is new merely because it is new.

6) Try to dwell in situations of intrinsic value and to act rather than being busy.

7) Appreciate ethnic and cultural differences among people; do not view the differences as threats.

8) Maintain concern about the situation in developing nations, and attempt to avoid a standard of living too much higher than that of the needy (maintain a global solidarity of lifestyle).

9) Appreciate lifestyles that can be maintained universally - lifestyles that are not blatantly impossible to sustain without injustice toward fellow humans or other species.

10) Seek depth and richness of experience rather than intensity. 
11) Appreciate and choose, when possible, meaningful work rather than just making a living.

12) Lead a complex, not complicated, life, trying to realize as many aspects of positive experiences as possible within each time interval.

13) Cultivate life in community (Gemeinschaft) rather than in society (Gesellschaft).

14) Appreciate, or participate in, primary production - small-scale agriculture, forestry, fishing.

15) Try to satisfy vital needs rather than desires.

16) Attempt to live in nature rather than just visiting beautiful places; avoid tourism (but occasionally make use of tourist facilities).

17) When in vulnerable nature, live 'light and traceless'.

18) Appreciate all life-forms rather than those considered beautiful, remarkable, or narrowly useful.

19) Never use life-forms merely as means. Remain conscious of their intrinsic value and dignity, even when using them as resources.

20) When there is a conflict between the interests of dogs and cats (and other pet animals) and wild species, try to protect the wild creatures.

21) Try to protect local ecosystems, not only individual life-forms, and think of one's own community as part of the ecosystems.

22) Besides deploring the excessive interference in nature as unnecessary, unreasonable, and disrespectful, condemn it as insolent, atrocious, outrageous, and criminal - without condemning the people responsible for the interference.

23) Try to act resolute and without cowardice in conflicts, but remain nonviolent in words and deeds.

24) Take part in or support nonviolent direct action when other ways of action fail.

25) Practice vegetarianism.

\section{Conclusion}

Baer (2012:294) offers some important insight into why one would undertake the task of exploring ecologically sensitive attitudes:

Obviously, eventually the human species, like so many other species that have inhabited this planet, will become extinct, if not due to 
developments of our own making then due to natural events over which we have little or no control. Yet it seems that we as a species can exert some degree of agency or control over our fate during the course of this pivotal century with respect to our some 5 or 6 million years on this planet.

The proclamation of the ability to 'exert some degree of agency or control over our fate' is much-welcomed optimism considering the depressing and worrying picture of the state of the planet's ecosystems, and socio-political and economic entities that by default perpetuate ecologically problematic businessas-usual. Acknowledging the route that history has actually taken, where dominant institutions have arisen and homogenised the globe (Nadar via Steger 2009:120), it is clear that business-as-usual will not simply change the way it operates. This is perhaps best exemplified by the paradoxical capitalist commitment to growing or dying (Kovel 2006). As each barrier to growth is overcome, be it an ecological barrier, social barrier, technological barrier, etc., capitalism and its array of global sub-systems steams ahead regardless of the intentions of employees, citizens, or CEOs. This is what the system requires endless growth. Kovel (2006:51) refers to this demand as 'the cancerous imperative to expand'. Something that grows endlessly, like cancer, Thomas Princen reminds one (2010:32-33), cannot do so forever:

[T] he economy depends on increasing consumption, but ever-increasing consumption strains ecosystems, both resources (soil and water, for instance) and waste sinks (the oceans and atmosphere). .... A system that grows endlessly crashes. Think of cancer cells, debtridden mortgages, fisheries. It defies logic, not to mention a few wellknown laws of physics..., to presume that with continuing growth in consumption, that is, continuing growth in the total throughput of material and energy through our economy - the current economy will not crash.

It is in this context that Hawken's analogy of humanity's immune system is so important. He saw the immune system in the one to two million organisations that constituted what he called an unconventional, unnamed movement. In this paper, several less obvious examples of ecocentrism have been added as nodes on the immune system. The ways of older cultures are predicated on the notion 
of interconnection and a conception of nature as inherently valuable. The unnamed movement that consists of hundreds of thousands of groups working against social and ecological exploitation are dispersed across the globe. The Occupy Movement created a temporary example of a more cooperative form of people living together, and it succeeded in getting the message out that tens of millions of people world-wide are willing to group together in solidarity against unjust economies and systemic ecological degradation. Eisenstein reminds one that a different kind of economy is conceivable, an economy that can be built according to ecological principles that must be respected if humanity is to survive with any sense of dignity. Finally, Naess provides considerable and specific detail about the deep approach to ecology, unavoidably implying that important attitudinal changes need to take place at the level of the individual and at the level of society if substantial responses to the ecological crisis are to occur.

\section{Acknowledgements}

This work is based on research supported by the National Research Foundation of South Africa (Grant Number 99188, SARChI Chair in Identities and Social Cohesion in Africa, Nelson Mandela University). Opinions, findings, conclusions and recommendations expressed in this work are those of the authors alone and the NRF accepts no liability whatsoever in this regard.

The author also acknowledges research support he received during his $\mathrm{PhD}$ (2014 - 2017) from the National Research Foundation, and the University of the Free State, South Africa.

\section{References}

Abram, D. 1997. The Spell of the Sensuous: Perception and Language in a More-Than-Human World. USA: Vintage Books.

Baer, H.A. 2012. Global Capitalism and Climate Change: The Need for an Alternative World System. UK: AltaMira Press. https://doi.org/10.1142/97898143669840023

Barnosky, A.D. E.A. Hadly, J. Bascompte, E.L. Berlow, J.H. Brown, M. Fortelius, W.M. Getz, J. Harte, A. Hastings, P.A. Marquet, N.D. Martinez, A. Mooers, P. Roopnarine, G. Vermeij, J.W. Williams, R. Gillespie, J. Kitzes, C. Marshall, N. Matzke, D.P. Mindell, E. Revilla \& A.B. Smith 
2012. Approaching a State Shift in Earth's Biosphere. Nature 486,52: 52 - 58. Available at:

https://www.nature.com/articles/nature11018 (Accessed 17 September 2018.) https://doi.org/10.1038/nature11018

BBC 2012. Viewpoint: Manuel Castells on the Rise of Alternative Economic

Cultures. Available at: https://www.bbc.com/news/business-20027044 (Accessed 13 August 2018.)

Buchanan, I. 2015. September 17, 2011: Occupy without Counting. In Conio, A. (ed.): Occupy: A People Yet to Come. London: Open Humanities Press. Derbyshire, J. The Contradictions of Capitalism: An Interview with David Harvey. Available at:

http://www.prospectmagazine.co.uk/blogs/jonathan-derbyshire/thecontradictions-of-capitalism-an-interview-with-david-harvey (Accessed 13 August 2018.)

Eisenstein, C. 2011. Sacred Economics: Money, Gift and Society in the Age of Transition. USA: North Atlantic Books.

Diamond, J. 2005. Collapse: How Societies Choose to Fail or Succeed. USA: Penguin.

Fratianni, M. \& F. Marchionne 2009. The Role of the Banks in the Subprime

Financial Crisis. SSRN Electronic Journal 2009,1. Available at: https://papers.ssrn.com/sol3/papers.cfm?abstract_id=1383473 (Accessed

17 September 2018.) https://doi.org/10.2139/ssrn.1383473

Hadot, P. 2006. The Veil of Isis: An Essay on the History of the Idea of Nature. Chase, M. (trans.). Cambridge, MA: Harvard University Press.

Hardoon, D. 2017. An Economy for the 99\%. UK: Oxfam GB.

Hartmann, T. 1998. The Last Hours of Ancient Sunlight. UK: Hodder and Stoughton.

Harvey, D. 2010. The Enigma of Capital and the Crisis of Capitalism. USA: Oxford University Press.

Hawken, P. 2007. Blessed Unrest. UK: Penguin.

Hoyer, K.G. 2012. Ecophilosophy and the Environmental Debate. In Bhaskar,

K., G. Hoyer \& P. Naess (eds.): Ecophilosophy in a World of Crisis:

Critical Realism and the Nordic Contributions. UK: Routledge.

Inman, P. \& P. Kingsley 2011. Inside Job: How Bankers Caused the Financial Crisis. Available at:

https://www.theguardian.com/film/2011/feb/17/inside-job-financialcrisis-bankers-verdicts (Accessed 13 August 2018.) 
Heidegger, M. 1977. The Question Concerning Technology and Other Essays. Lovitt, W. (trans.). New York and London: Garland Publishing, Inc.

Kovel. J. 2006. The Enemy of Nature: The End of Capitalism or the End of the World? London and New York: Zed Books.

Mason, P. 2015. The End of Capitalism has Begun. Available at: https://www.theguardian.com/books/2015/jul/17/postcapitalism-end-ofcapitalism-begun?CMP=share_btn_link (Accessed 13 August 2018.)

McLendon, R. 2011. Environmentalists Join The 'Occupy Wall Street' Fray. Available at:

https://www.forbes.com/sites/eco-nomics/2011/10/07/environmentalistsjoin-the-occupy-wall-street-fray/ (Accessed 13 August 2018.)

McDonough, W. \& M. Braungart 2002. Cradle to Cradle: Remaking the Way We Make Things. New York: North Point Press.

Naess, A. 2008. The Ecology of Wisdom: Writings by Arne Naess. In Drengson, A. \& B. Devall (eds.). USA: Counterpoint. by

Occupy Movement, The. About. Available at: http://occupywallst.org/about/ (Accessed 13 August 2018.)

Piketty, T. 2014. Capital in the Twenty-First Century. Goldhammer, A. (trans.). USA: The Belknap Press of Harvard University Press.

https://doi.org/10.4159/9780674369542

Pittaway, D.A. 2017. Broadening the Context of the Ecological Crisis: Featuring the Orphic and the Promethean. PhD Thesis, University of the Free State, South Africa.

Princen, T. 2010. Treading Softly: Paths to Ecological Order. USA: MIT Press. https://doi.org/10.7551/mitpress/8573.001.0001

Setereng, S.K. 2012. Gaia versus Servoglobe. In Bhaskar, K., G. Hoyer \& P. Naess (eds.): Ecophilosophy in a World of Crisis: Critical Realism and the Nordic Contributions. UK: Routledge.

Sheldrake, R. 1991. The Rebirth of Nature. Vermont: Park Street Press.

Vetlesen, A.J. 2012. Technology, Nature and Ethics. In Bhaskar, K., G. Hoyer

\& P. Naess (eds.): Ecophilosophy in a World of Crisis: Critical Realism and the Nordic Contributions. UK: Routledge.

White Junior, L. 1967. The Historical Roots of Our Ecologic Crisis. Science 155,3767: 1203-1207. Available at:

http://science.sciencemag.org/content/155/3767/1203/tab-article-info

(Accessed 17 September 2018.)

https://doi.org/10.1126/science.155.3767.1203 
David Anthony Pittaway

WWF 2016. Living Planet Report 2016: Risk and Resilience in a New Era. WWF International: Switzerland.

David Anthony Pittaway

Postdoctoral scholar

SARCHI Chair: Identities and Social Cohesion in Africa

Nelson Mandela University, Port Elizabeth

pittaway@gmail.com 